\title{
TOWARDS A SHARED RESPONSIBILITY FOR QUALITY IN THE PARTICIPATORY ARTS: KEY INSIGHTS INTO CONDITIONS UNDERPINNING QUALITY
}

\section{ABSTRACT}

The ArtWorks programme has succeeded in generating deeper insights into the realities of participatory arts practice in the UK, in particular the conditions needed to achieve quality and the extent to which these are enabled. In parallel with ArtWorks research, in 2014 Creative Scotland commissioned a detailed analysis of the extant 'body of knowledge' concerning quality, which uncovered a number of generic concepts of quality held in the commercial world which are of profound relevance to the participatory arts and the questions currently being explored by the sector.

When such 'global' perspectives- about the inherent nature of quality, how to 'build it in' to a product and how to manage quality outputs - are considered alongside evidence and testimony from the sector captured by ArtWorks, several important learning points emerge: One, that quality does not reside just in the art or work undertaken with participants 'on the day' but stems from a holistic process consisting of several preceding phases including conception, design and planning, each of which contain quality components. Two: quality in the participatory arts is not solely determined by the artist and what they deliver 'in the room', but is directly affected by a range of key decision makers some of whom may be far removed from the project itself, but who nonetheless influence whether the experience of the participants is a quality one. Three: there are recognisable essential preconditions for quality that appear to be common across participatory arts practice. Many of these are outside the artist's direct control and are often missing from projects, undermining the chances of quality experiences for participants.

The seminal theory of US researchers Seidel et al (2010) constructing the interconnectedness of decision makers provides vital context for appreciating the roles and responsibilities of a wider group of stakeholders (including commissioners, employers and funders) in the achievement of quality experiences for participants. These observations lead to important recommendations for greater stakeholder engagement and responsibility; again gaining especial pertinence in light of evidence generated by ArtWorks.

This article outlines each of these points in detail, reconstructing the logical development of key insights contained in the Creative Scotland report, which was researched and written by this author. The core components of an optimum quality system are proposed and represented as features of a holistic framework.

\section{INTRODUCTION}

At the present time there is a move by the UK's arts councils to re-address the focus of their quality frameworks, conscious that existing mechanisms are 
missing some undefined element. In 2012 Arts Council England (ACE) commissioned a significant study, performed by the NFER, to identify the "values or principles that are considered important in creating quality in arts and culture by, with and for children and young people" (Lord 2012: i). At the same time Creative Scotland has sought to update the Quality Frameworks of 2007 and 2009 inherited from the Scottish Arts Council, recalibrating its focus on quality and how to define it, foster it, fund it and evaluate it (Blanche 2014:105). A great many practitioners from across the participatory arts 'sector' have become engaged on this issue through the ground breaking ArtWorks project, funded for five years across the UK by the Paul Hamlyn Foundation. ArtWorks has provided a vital platform for extensive consultations, studies and plenary events concerning quality in the participatory arts. The UK arts councils have been closely involved in the development and delivery of the ArtWorks initiative in the regions. All of this activity and focus on quality has created important new insights and understanding about quality in the participatory arts, taking us further into the concepts, processes and realities than ever before, and generating evidence and reporting of significant value.

In September 2014 Creative Scotland published a report collating and synthesising extant theories and literature concerning quality in participatory arts and sketching the components of an optimum quality framework for work in participatory settings. This endeavour, drawing on over 100 studies and reports on quality including the very latest publications and developments from ArtWorks (Blanche 2014: 26), encapsulates the new, informed and progressive understanding that has emerged about quality and how best to foster it. The study, entitled Developing a Foundation for Quality Guidance for arts organisations and artists in Scotland working in participatory settings and produced by this author, was able to draw on many important insights generated from the Artworks pathfinders, and to build on established findings from preceding work done by Arts Council England to define quality principles for learning.

The findings in the Creative Scotland study are based on literature from within the traditional participatory arts and arts education realms, but also deliberately draw from more generic or 'global' definitions of quality issuing from sources like the Chartered Institute of Quality and the American Quality Institute, providing some profound insights for the study.

Some of the most significant stepping stones towards the thesis presented here comprise a move towards a more holistic understanding of quality (Matarasso 2013), fundamental 'global' concepts from industrial contexts about quality systems (Marino 2007, CQI 2013a), and recognition through the work of Seidel et al (2010) of the influential role of project partners and stakeholders in enabling or hindering quality outputs and outcomes. These insights and conceptual 'steps' shall be laid out in this paper, building up a logical argument for the new conception of quality and culminating in proposed measures for a holistic quality system. 


\section{LOOKING AGAIN AT CONCEPTS OF QUALITY}

The position of recent commentators on quality in the arts and education is that it is possible now to move away from arguments around process versus praxis or product, described as "old ground" by Lord et al (2012). Instead, it is increasingly recognised that both process and product are components of a more holistic conception of quality. It is not a case of focusing on either-or, but recognising that quality occurs as a process during which product features may be built in or planned for.

This insight takes the participatory arts debate closer towards commercial concepts of quality systems, where the inherent quality of an item is purposely designed and needs to be inbuilt in order to produce a final product at the requisite standard.

Indeed, some global theories about quality held in the commercial world are that:

1. 'The quality of anything, while influenced by many groups, has to be first specified and then built in. It cannot be assured, audited, or tested into the entity.'

2. Once quality has been built in, 'subsequent deployment, operation, and maintenance processes must not degrade it' (Marino 2007).

The idea that quality can only be built in during the development process (Marino 2007) seems obvious when applied to commercial products. In a participatory arts context, the development process would equate to the planning, resourcing and situating of a project. Through the ArtWorks initiative, a more holistic view continues to develop of quality, acknowledging the influence of each phase of a project on ultimate quality and not just the creative/participatory phase. This holistic approach is exemplified by the Five Phases of Participatory Arts presented by Matarasso (2013), whereby each phase of a project is seen to influence the ultimate quality, and not just the creative/participatory phase.

Figure 1: Matarasso's Five Phases of Participatory Arts (adapted from Matarasso 2013: 

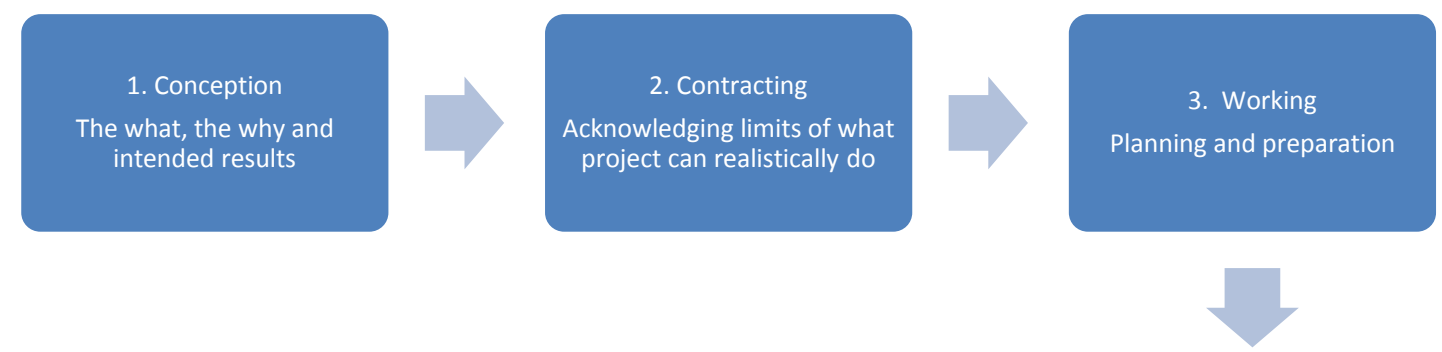

5. Completion

Is there continuing support

for participants? Is there

reflection, review, evaluation?
4. Creation

The project: is there a sense

of achievement for participants?

According to Matarasso, it is important to distinguish between different phases required for the development and delivery of a quality project, and to rationalise the different expectations that may be attached to each phase. Matarasso qualifies that even though it can never be absolutely guaranteed in advance that the final project or showcase will be an artistic success, the evidence shows that 'a good quality process can form a reliable precondition for creating good art' (Matarasso 2013: 9). This means that quality conditions can be planned for. If quality can only be planned for and 'built in' early in the process, then the only rational way to manage quality is to focus attention on fulfilling the conditions required for quality to occur.

These statements underline the importance of having clear guiding principles and stated aspirations for the work and a supportive environment for the work that provides the right conditions for quality outcomes. These arguments shall be developed further in the course of this paper.

\section{Continuous Quality Improvement}

The concept of Continuous Quality Improvement as an approach to raising standards has filtered through the public sector in recent years along with the realisation that if quality standards and expectations don't evolve and become raised over time, then notions of quality will quickly become outdated as a sector's capacity to provide excellent arts experiences increases (Seidel et al 2010: 45). Continuous quality improvement is a type of change that is focused on increasing the effectiveness and/or efficiency of an organisation to fulfil its policy and objectives (Blanche 2014: 47). Essentially it means 'getting better all the time' (CQI 2013b). As a continuous process, it is "a proactive, cyclical system of planning, doing, reviewing and improving - or enhancing what is delivered and how it is delivered" (Schwarz 2014: 9).

Continuous quality improvement forms the basis of HMIE's How Good Is Our ... framework, a thorough system for reflection and self-evaluation currently 
used by schools and deliverers of community learning and development (HMIE 2006). Other commentators on this subject have highlighted this as the most appropriate approach for quality development in educational and participatory arts settings (Bamford 2010; Schwarz 2014).

A meaningful quality framework therefore allows for artists to develop continually, and build capacity and excellence in the sector. Concepts of quality can evolve through dissemination of best practice, self-monitoring and self-renewing (Blanche 2014: 188). Crucially though, continuous quality improvement does not just concern self-reflection by artists, but also requires learning by all partners and consideration of whether the conditions are right for each kind of project or context. In seeking continuous improvement it is important to focus on good practice and known levers for improvement (Blanche 2014: 188).

Quality improvement can be considered then as more than a process, but as a cycle or as an upward spiral. This is what has been missing largely from funder approaches in the past (Blanche 2014: 119).

\section{Profound insights on quality from industry}

The study in 2014 undertaken for Creative Scotland took an intentionally broad approach in characterising the 'existing body of knowledge' about quality, drawing not only from studies concerning the participatory arts and learning, but also from generic or 'global' approaches to quality management articulated by sources such as the British Chartered Quality Institute (CQI). It was hoped to gain a more nuanced perspective on how quality is conceived as both an attribute and output (Blanche 2014) and to enrich the discussion within the context of the participatory arts.

Relying as it does on consumer satisfaction, experience and perception of products, the manufacturing industry could be perceived at the leading edge of thinking about quality. This broader perspective concerning quality as part of business management yielded fundamental insights for the research for Creative Scotland on how quality may be 'built in' to a project and a set of logical statements concerning means of establishing and maintaining quality features as well as rationalising where responsibility can realistically be allocated.

Schwarz (2014) offers a useful understanding of how the term "quality" is used in the arts sector: quality equates to something fit for purpose, meeting specifications and stakeholder expectations, achieving the very best results and outcomes. A quality judgement is also applied to how an organisation is managed, how services or projects are run, and the expertise of those who deliver the work (Schwarz 2014 cited in Blanche 2014: 44). Indeed the two overriding principles suggested by Downie (2011) for determining the quality of an arts project - fitness for purpose, and relevance to context - could be considered generic characteristics of quality whether we are talking about the arts or software. 
In the context of, say, manufacturing, the concept of quality production correlates with the kind of attributes summarised by Schwarz (2014) for the arts context. It is widely accepted that quality attributes and expectations need to be defined appropriately for different kinds of product, and that it is not possible to create a 'one size fits all' definition or approach (White 2010, Renshaw 2010). Indeed, Artworks' artist consultations reaffirmed the point that each project has a unique set of requirements, context and content and, as such, needs to be developed individually and assessed according to its specific context and objectives. The report by Salamon warned that it is therefore counterproductive to adopt a formulaic approach to establishing quality or seek to replicate processes from other contexts or settings (2013: 17).

\section{Minimising Variation}

A useful benchmark is the Chartered Quality Institute's determination of what quality is not:

"Quality is not perfection, a standard, a procedure, a measure or an adjective. No amount of inspection changes the quality of a product or service. Quality does not exist in isolation - there has to be an entity, the quality of which is being discussed. Quality is not a specific characteristic of an entity but the extent to which that characteristic meets certain needs. The value of the characteristic is unimportant - it is how its value compares with customer needs that signifies its quality" (CQI 2013a)

This definition could apply in its entirety to participatory arts, particularly the statement that is the consumer or recipient whose experience ultimately connotes quality.

Within industry, this concept of quality is expressed as a process of minimising variation: the difference between an ideal and an actual situation. According to the American Society for Quality (ASQ) improving quality therefore involves reducing the degree of variation between the ideal as a standard of perfection (ASQ 2014) and what the recipient experiences. As for the standard of perfection or 'excellence', this has to be uniquely defined for each product by the stakeholders (ASQ 2014).

ASQ point out that the fact that 'we can strive for an ideal but never achieve it', meaning that 'stakeholders always experience some variation from the perfect situations they envision', is what provides the conditions by which improvement and progress are possible (ASQ 2014).

The British Chartered Quality Institute qualifies this further, pointing out that "if quality is the result of a comparison between what was required and what was provided" then it is ultimately "judged not by the producer but the receiver" (CQI 2013a). This is especially pertinent to considerations of quality in participatory arts where the underlying objectives and principles for the work is some form of transformation or experiential journey for the participant. Up 
until now it is fair to say that the voice of participants has not been a major driver in determining policy direction on participatory arts, and certainly not to the extent that in a market-driven industry the customer needs, preferences and habits would be used to inform quality standards. The point that participants need to be consulted more has been raised by other commentators, including Artworks (Salamon 2013), and remains an important area for research and development in this topic.

\section{Responsibility for quality}

From industry we can also gain extremely helpful perspectives on what is reasonable practice for assigning responsibility for quality. The Chartered Quality Institute determines that an individual cannot be made responsible for guaranteeing quality; they may only make efforts relative to quality ie they can specify quality requirements, perform functions to satisfy quality requirements, or make an assessment of the quality of something (CQI 2013a). The Institute holds that even at a management level all that a Quality Manager can do is "to enable others to achieve quality by providing encouragement, leadership, training, tools, techniques and performance data" (CQI 2013a). At the highest management level (ie the Chief Executive or board of directors) a reasonable expectation of responsibility is to provide skilled leadership and facilitate results on quality performance (CQI 2013a).

Crucially, the view of the CQI is that when someone is assigned responsibility for quality, with that responsibility needs to come the right to "cause things to happen", by which they mean authority to control the processes that deliver the output, the quality of which the person is responsible (CQI 2013a, cited in Blanche 2014: 44).

This statement is of vital significance to how we think about responsibility for quality in the arts. If we accept the position of the Chartered Quality Institute, then if an artist is asked to demonstrate and account for the quality of their work, say in a participatory arts setting (but it could equally be any other context), then it is only reasonable if that artist has had complete control over all aspects and stages of the output. The reality for many participatory arts projects, according to insights generated through various Artworks research projects, is that many aspects of the project are outwith the control of the artists (Pheby 2012, Dean 2012 supported by Seidel et al 2010). This evidence from ArtWorks is explored in detail ahead in this paper.

\section{VARYING LENSES ON QUALITY}

When we consider the different vantage points of groups of stakeholders involved in participatory arts work, it is easy to appreciate that there are likely to be differing ways of viewing quality, different aspects of the work prioritised, and a range of expectations. Add to this the injunction that ideas about what constitutes quality can and should vary across settings (Seidel et al 2010: 45; Renshaw 2013: 51; Salamon 2013:17), then it becomes clear that when trying 
to define and manage quality it is necessary to take into account a number of different lenses on quality.

Exploring quality in arts education in their study in 2010, Seidel et al identified several dimensions of quality experienced by separate stakeholder groups, and characterised these as individual 'lenses' through which to view quality. Building on this and similar concepts proposed by Bamford (2010), the recent analysis for Creative Scotland expands on this concept to consider it more squarely within a participatory arts context. Individual lenses are discussed in terms of: participant experience; artist intentions and practice; the commissioner or partner's intentions; the dynamic of the setting and group; and the nature of the project facilities (Blanche 2014).

Figure 2: Quality Lenses in Participatory Arts

(Blanche 2014)

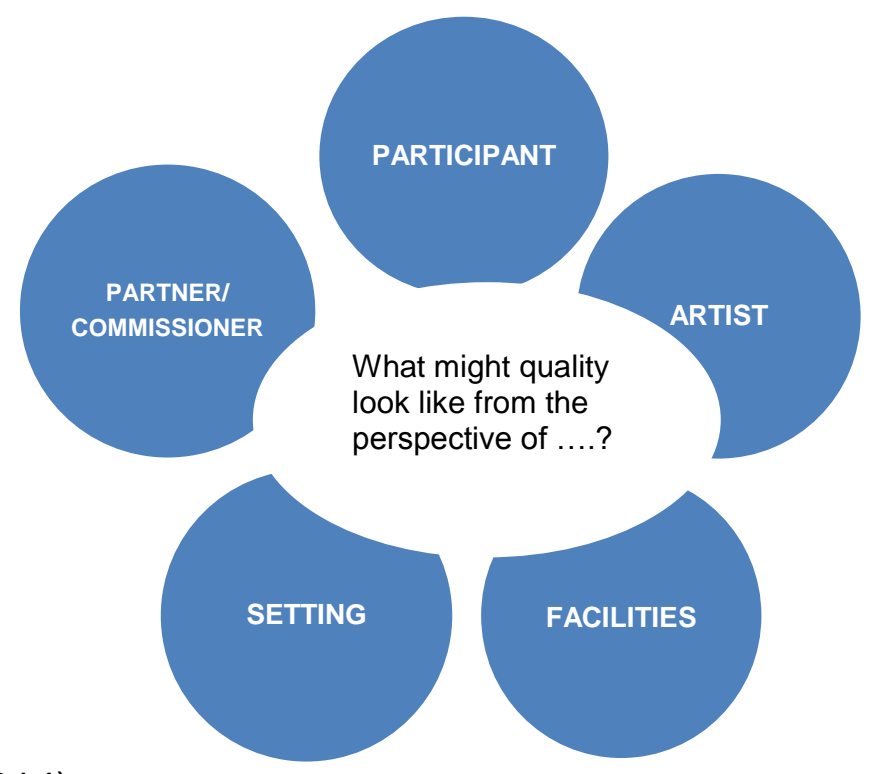

Drawing from various studies we may delineate the kinds of 'qualities' valued when looking through these lenses.

For participants quality tends to concern depth of engagement and the impacts arising from that. Generally speaking, aside from the quality of their artistic engagement, participants place value on a safe environment in which to experiment, and to feel respected and connected to the project (Salamon 2013 cited in Blanche 2014: 54).

Consultations with artists reveal that they are motivated to generate positive impacts for participants and to 'enable people who are unheard to find their voice' (Lowe 2011). Artistic challenge, professionalism and integrity are also core aspects of quality (Leighton-Kelly 2012).

Employers or commissioners tend to prioritise professionalism and good governance when defining quality work. They think in terms of the 'quality' of 
the artists delivering the project, and assess how the project interplays with the culture of the host organisation (Bamford 2010). They also want positive experiences for their participants: the 'excellence' of the art itself is not necessarily a high priority as long as it has impact (Sellers 2014).

In terms of the setting for the project, quality is associated with how suitable the project is for the specific context ie healthcare, community, and how well it has been designed to meet specific needs. The ways in which participants treat each other, learn with and from each other, and feel about being together are also key quality factors in this context (Seidel et al 2010).

Finally, when the focus is on facilities, priority factors include the physical environment or space for the work and the quality of materials.

An important finding from Seidel et al (2010) is that the quality of any of these elements cannot stand alone but all contribute to the quality of the experience, underlining once more the holistic nature of quality.

The task, then, is to formulate an approach to quality that is a holistic one enabling different 'qualities' of each piece of work to be acknowledged, as well as recognising that experiences and expectations of quality will vary according to different stakeholders in the project (Blanche 2014: 10).

\section{THE CRUCIAL ROLE OF THOSE BEYOND 'THE ROOM’}

The central role in quality of partner organisations as commissioners, employers and hosts for participatory arts work is gaining increasing recognition. While artists are at the forefront of delivering arts work and interventions with participants, a great many other wider dynamics have been found to directly affect the quality of the experience of those who are engaged 'in the room' (Seidel et al 2010). These dynamics are often controlled by partner organisations or employers (characterised by Seidel et al as 'those outside the room') who are not directly involved in delivering the arts work, and who typically have different relationship to participants than that of the artist interacting creatively with them (Blanche 2014: 81 ). This situation is reinforced by perspectives from industry: writing from a commercial standpoint, Marino states that everyone working on a product, from the project manager to the most junior member of staff, affects the quality of what is produced (Marino 2007: 22).

There are countless decisions that influence the delivery of a participatory arts project and the likelihood that participants will have a high quality experience. Because of the nature of participatory arts and the variety of settings in which they take place, there are inevitably multiple decision makers as well (Blanche 2014: 81). Recent reporting from ArtWorks offers a helpful classification for different types of employers and commissioners of participatory arts work:

'Creating organisations': National or regional arts organisations which develop participatory arts projects across art forms as an integral part 
of their mission and remit. These 'creating organisations' usually have dedicated staff and/or project managers to support the development of successful participatory arts projects for participants, artists and 'buyers'. They also have an impact on artist recruitment (Sellers 2014: 8-10).

'Buying organisations': Generally organisations outside of the arts sector such as schools, the National Health Service, the Prison Service and local authorities. Such buyers may commission arts organisations to deliver services or develop arts projects put out to tender. They often desire to provide long term impacts for their client group, often through short projects with limited contact time, implying at times a flawed understanding about the nature and quality of participatory work (Sellers 2014: 11-13)

'Artist commissioners': Individual artists who act as employers in the sector, recruiting other artists to work with them on projects (Sellers 2014: 14).

Clearly among the above employer types there is scope for significant variation in expectations for, familiarity with and understanding of participatory arts, as well as a diverse range of possible settings for such work. A key insight on quality that has to be made central in any quality management approach is that the people commissioning, funding or employing artists for participatory arts work have a significant influence over whether quality can be achieved. This is explained through Seidel et al's theory on the interconnectedness of decision makers.

Seidel et al's research identifies three generic groups of decision makers who influence the quality of arts learning experiences: the people 'in the room' delivering or engaged in the project or activity; those just outside the room closely involved in designing and facilitating the project; and decision makers furthest from the room setting organisational standards or parameters and determining resources.

Figure 3: Influence of Decision makers on Participants' Experience 


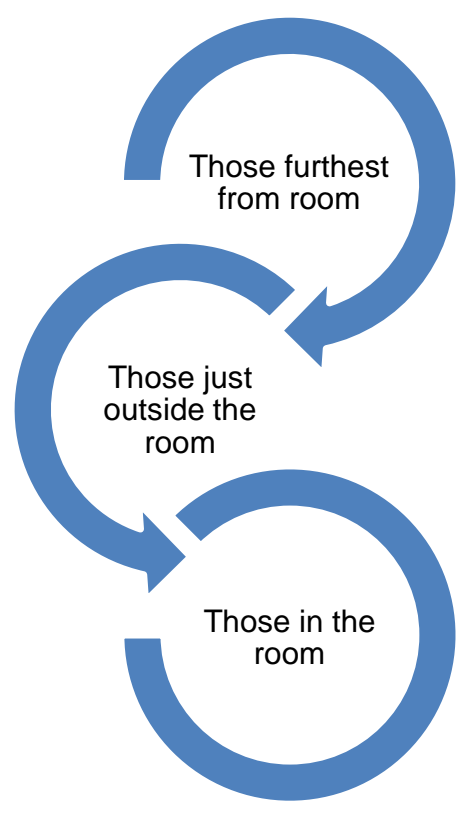

Those in the tend to be participants, room

artists and

occasionally carers, support aides, parents

Those just are parties who may outside visit the room in which the room arts experiences occur, like project managers, arts coordinators and site liaisons.

Furthest include high level away from decision makers who the room rarely, if ever, enter the room, yet have significant control over decisions relating to the work, i.e. funders, board members, employers, legislators.

Seidel et al's detailed study reports that that those just outside the room and those even further away who may never or rarely enter the room, have a powerful effect on the likelihood that those in the room will have a high quality experience. Their decisions are also critical to whether that quality can be achieved and sustained consistently over time and across settings (Seidel et al 2010).

There is a logic to how this occurs. Decision makers who are directly engaged in the work (ie the artist and the participants) tend to decide 'in the moment of the experience' on questions relating mainly to the content and nature of the work being undertaken. Measures are taken to enhance the experience of those in the room. However Seidel et al argue that decisions made by those further away from the room are often made well in advance of the moment and, in the case of higher level policies, may affect many participants in multiple projects (Seidel et al 2010: 65). Within challenging settings with, for instance, participants with special needs, it is easy to appreciate the veracity of this observation (Blanche 2014: 81).

Core decisions that are likely to determine quality relate to participant selection, the content and level of engagement, resources, staffing, partnerships and evaluation (Seidel et al 2010: 65). Such organisational and programme decisions are normally made by decision makers beyond the room. Problems occur when there is disconnect between those directly engaged in the delivering the work, who experience the realities and needs of 
the participants and artistic requirements, and those who determine organisational requirements, frameworks and access to resources.

Because decisions in each circle are inter-related and ultimately affect the quality of the experiences in the room, Seidel et al argue that 'successful systems of decision making recognise the delicacy and likelihood of mistakes made in the outer circle and provide frequent, open, and dynamic channels of communication with the explicit purpose of informing the outer circle decision makers' (Seidel et al 2010: 63). Quality therefore depends on meaningful dialogue across the circles on the real needs and priorities in a specific setting. As part of this, a quality process needs to be founded on clearly articulated conditions for quality, and articulated expectations. Seidel et al echo this with the sentiment that "the challenge for everyone is the degree to which they are in communication, working together to assure not only the quality of the inner circle experience, but also the future of those experiences" (Seidel et al 2010: 67).

\section{CURRENT INDICATIONS OF DISCONNECT}

In the past four years ArtWorks has investigated further than ever before into the realities for artists of working with partners in participatory arts settings.

A report by Artworks North-East captures discussions from a number of artist focus groups, reporting instances where:

- Stakeholders influence outcomes in ways that practitioners (whose focus is less likely to be goal-centred) find unsatisfactory

- Stakeholders enforce content control where practitioners don't believe this is appropriate (Pheby, 2012).

Results from ArtWorks artist consultations in Scotland highlight similar problems in partnership working in participatory arts, specifically:

- Under-developed relationships between artists and host/commissioners;

- Unrealistic commissioner expectations; and

- The absence of a common language across different sectors/stakeholder groups (Consilium 2012).

Artworks report, Learning from the Research (Kay 2012), cites perspectives from commissioning partners (e.g. NHS, prison service, schools and local authorities). It reports 'issues of quality assurance related to skills, knowledge and experience, and the identification of appropriate interventions by artists' (Kay 2012: 18).

Further testimony from the points of view of both artists and partners is offered by the Institute for Research in the Social Sciences (IRISS) in a report investigating The Arts in Scottish Social Services. The report discusses what is considered quality work, and how crucial partnerships are to delivering it. The IRISS research reports difficulties experienced by artists in achieving sufficient 'buy in' by social services staff for participatory arts projects (Pattoni 
2013: 12). Among the key insights generated from the research is that arts activities are most effective when social care practitioners are actively involved and jointly working with the artist; assigning clear roles can assist this process (Pattoni 2013: 13)

If we accept the lesson from industry that 'once quality has been built in to a product, subsequent deployment, operation and maintenance processes must not degrade it' (Marino 2007: 21), then we see how important it is that the influence exercised by outer circle policy and decision makers is directed towards fostering quality rather an undermining it.

On the basis of their observations, Seidel et al caution that the challenge of creating a meaningful dialogue among partners is profound, and it doesn't happen without intentionality and serious effort (Seidel et al 2010: 69). The goal for those involved in participatory arts projects should be to achieve alignment between all stakeholders on what constitutes quality for them, what they want their quality experiences to look like and how best to create these experiences in the specific setting (Blanche 2014: 87).

\section{RECOGNISED CONDITIONS FOR QUALITY}

In terms of deciding what constitutes quality in a specific context, and what the quality experience will look like or feel like for participants, this relates to a set of aspirations, guiding principles and objectives. Arts Council England and Creative Scotland are each working with the arts sectors to define the kind of features inherent in quality participatory arts and learning. This understanding is being used to formulate frameworks for quality and benchmarks for good practice. Generally speaking, these revolve around: artistic excellence; authenticity and social relevance; being inspiring and engaging; being participant-centred; purposeful, active and hands-on work; progression for participants; participant ownership of the work; being suitably situated and resourced; and work that is properly planned, evaluated and safe (Blanche 2014: 60). It is reasonable to expect that the principles and expectations for each piece of work will vary according to the nature of the project, the participants and the setting.

In terms of how best to foster quality experiences, however, much has been learned through the ArtWorks programme on the key elements that are needed in order to achieve quality. So, on top of the revelation that control over quality extends beyond the participatory arts practitioner alone, we now also have a more explicit understanding of what factors or conditions are needed to achieve quality work and quality experiences.

The findings from several studies published by ArtWorks can be synthesised into the following list of main preconditions for quality participatory arts work. According to practitioners and artists, there need to be:

- Sufficient resources, including fit for purpose environment

- Sufficient time, for planning, building relationships and implementing project

- Designed and resourced for participants' needs and support 
- Opportunities to reflect, adapt, evaluate

- Realistic aims

- Understanding of artist and partner roles

- Buy-in and Trust by all parties

- Clear and realistic expectations

- Democratic decision-making (artist-partner-participant)

(Blanche 2014 drawing from Lowe 2011, Dean 2012, Salamon 2013)

While several of the conditions above may seem plainly obvious, for instance having sufficient time, resources and appropriate content, the significant insight revealed through the ArtWorks research is that these preconditions for quality are not always in place for participatory arts projects, meaning that expectations of quality outputs and outcomes are heavily undermined. When ArtWorks investigated how often these quality factors occur from artists' point of view, it found that many of the essential and important factors occur only sometimes, and many happen rarely (Dean 2012: 27-28), indicating that there are often significant obstacles facing artists in trying to achieve quality experiences for participants.

Figure 4: Occurrence of Essential and Important Factors, from Artists' viewpoint

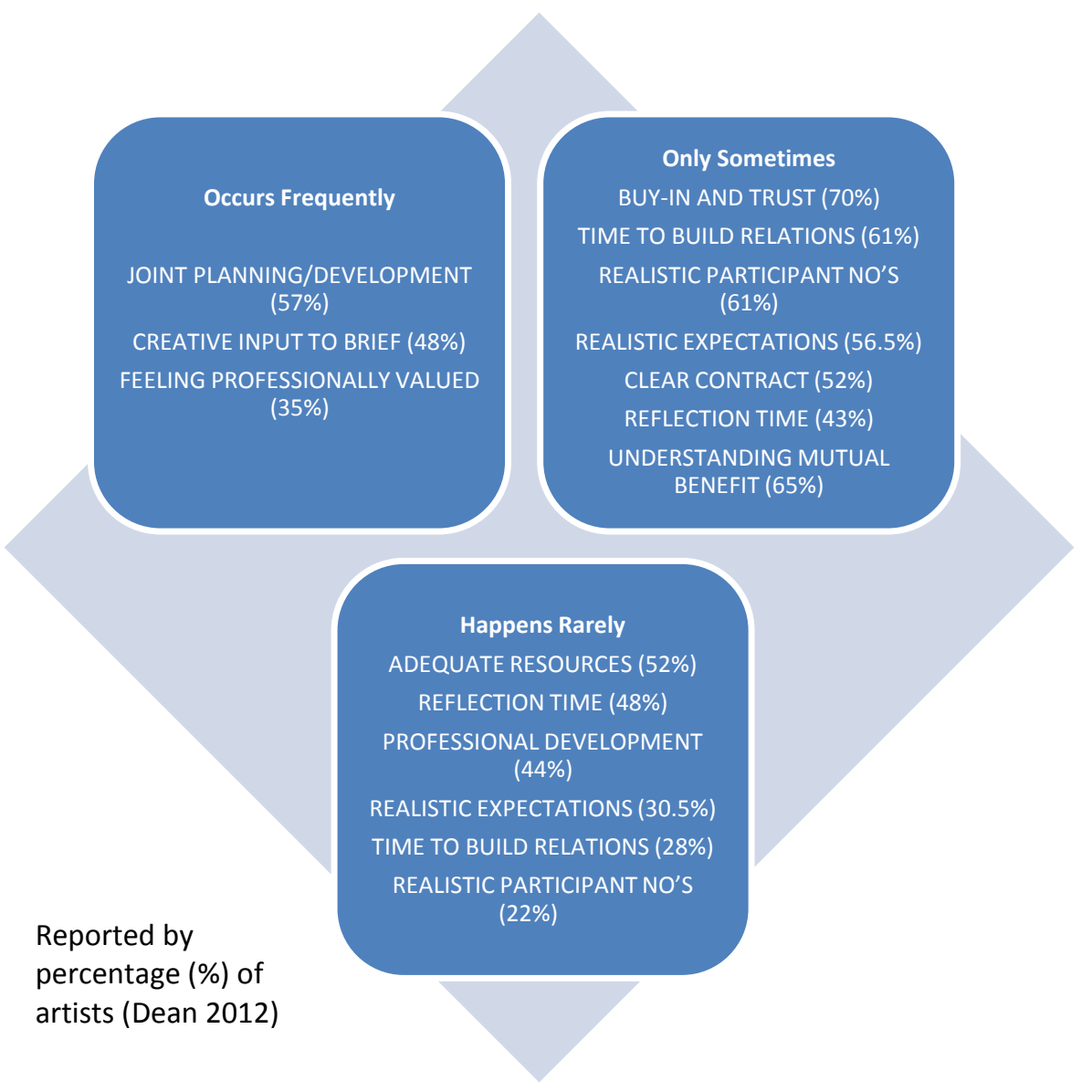

(Diagram from Blanche 2014, representing data reported in Dean 2012) 
ArtWorks Scotland repeated the study in 2013 to gain perspectives on these same quality conditions from project partners (who were defined as people working with artists as employers, managers, commissioners or coordinators). While this survey of partners found general consensus on the importance of the factors, there was a significant variation in how often partners perceived these actually happening, with partners reporting greater incidence of key factors in practice than the artists (Blanche 2014: 80 citing Dean 2013). On the important issue of 'expectations of what can be achieved in the time and resource', over $30 \%$ of artists thought this rarely happened compared to $9 \%$ of partners and $43.5 \%$ of partners thought it often happened compared to $13 \%$ of artists (Dean 2012; Dean 2013). Likewise, on the issue of 'adequate resources - financial and other - to support planning, delivery and evaluation', $4 \%$ of artists perceived this happening often compared to $30 \%$ of partners (Dean 2012; Dean 2013).

So, ArtWorks have revealed that there are recognised elements that should be built in to projects as reasonably reliable preconditions for quality, while also showing us that a lot of the time these conditions are not in place. Furthermore, partner perceptions of the presence of quality conditions vary significantly from those of artists. This evidence strongly implies that there is a limit to which artists delivering participatory arts work with partner organisations are able to control important quality factors. Seidel's observations on the impact of external stakeholders assume particular pertinence in light of this evidence. It seems clear that if we want to foster conditions for quality work and quality outcomes, then such disparities and disconnect need to be resolved.

\title{
THE NECESSITY FOR UNDERLYING QUALITY PRINCIPLES
}

As mentioned before, it is recognised that any assessment of quality must stem from a set of overarching aims or principles for the work. Defined principles are considered essential to establish a common understanding of what is desired before being able to judge whether quality has been achieved. The reality of this is apparent even from the perspective of the software manufacture industry, which is the context for the following statement:

\begin{abstract}
"Without clear articulation of the quality attributes, it is impossible to develop a product or determine whether the finished product has the needed quality. A specification is required to communicate to others which attributes and attribute values constitute the product's quality. Contractually, this specification is critical." (Marino 2007)
\end{abstract}

With respect to participatory arts, the need for a quality framework based on clearly defined principles is equally compelling. This is what has been missing from historic quality frameworks devised by the Scottish Arts Council, currently being remodelled by Creative Scotland. It is interesting to note that in an industrial context, such specification is deemed critical to any contract. The implication of Marino's statement is that no rational manufacturer would undertake to construct a product, thereby taking responsibility for the quality of it, without specifications on its desired attributes, functionality and qualities. 
Yet historically artists have been asked to deliver and evaluate quality participatory arts work without a defined set of principles against which the quality is to be characterised or measured (Blanche 2014: 9).

In the context of participatory arts it stands to reason that such specifications, or quality principles, are needed in order to know whether the work has met its purpose and how it can be further improved. This is a generic requirement, regardless of context or industry. It follows that any quality principles need to stem from what is trying to be achieved, which makes it important to have recognised purpose, objectives and aspirational values for doing the work (Blanche 2014:57)

\section{WHERE DOES THIS TAKE US? THE IMPLICATIONS OF THIS NEW UNDERSTANDING}

First: conditions for quality need to be set in place, requiring buy-in from all stakeholders

It is clear that one of the only aspects about quality that can be managed is the conditions under which the work is developed and takes place. We can consider such conditions as quality features that need to be built in to the work, the same as with a commercial product. Recognising the conditions and ensuring that they are in place is a process that must involve all the partners/stakeholders who have an influence over what happens "in the room" (Seidel et al 2010).

As such, a key learning point from the Creative Scotland report is that a management approach for quality should be focused on facilitating optimum quality conditions (Blanche 2014: 121). The reality that it is not possible to "assure, audit or test quality into an entity" (Marino 2007: 35) shows that efforts need to focus on understanding what might improve the participant experience (Schwarz 2014: 5) and build in those elements. As Matarasso points out, it must also be acknowledged that outcomes will be subject to active variables including the artist and the individual participants (Matarasso 2013).

Some of the conditions listed in this paper relate to resources, which have obvious implications for project budgets and costs. Realistic costs for creating appropriate conditions (for instance sufficient planning and reflection time) will need to be rationalised by funders likes Creative Scotland as part of an informed quality system, if a conceptual shift is to occur.

Second: work should be planned, delivered and ultimately evaluated against defined guiding principles that reflect the needs of all of the stakeholders

It is accepted by policymakers that any meaningful quality framework must be underpinned by defined guiding principles. Arts Council England was the first to proffer a set of principles for arts learning work with children and young people, based on extensive consultation and recommendations 
commissioned from the National Foundation for Education Research (NFER) in 2012. The impetus for the research for Creative Scotland reported in this article was to highlight the way forward towards developing a meaningful and effective quality framework for the participatory arts in Scotland (Blanche 2014: 23).

The same precept applies in non-arts contexts. Marino states that defined principles are essential to establish a common understanding of what is desired. Without them it is not possible to judge whether quality has been achieved (Marino 2007). Crucially, within an industrial context, such advance specification is deemed critical to any contract, and should be recognised as such for the arts as well. Only by working toward clear, shared goals can all of the parties who contribute to the ultimate quality of the participatory arts 'product' and experience be confident of achieving it.

But it is important to avoid a prescriptive approach to quality. All commentators on quality in participatory arts agree that the quality impacts cannot and should not be prescribed (Bamford 2010, Lowe 2011, Downie 2011, Renshaw 2013, Taylor 2013, Schwarz 2014). Not only is it futile to try to inspect quality into something, but the experience and conditions for quality will always be different depending on the nature of the project and the participants. As an example, it stands to reason that National Theatre of Scotland and a small youth arts project are going to be working from a different starting point and to very different expectations (Blanche 2014: 51).

Any quality framework needs to allow artists less experienced and with smaller budgets to feel they can achieve quality (Blanche 2014:124), and this should be possible with a set of aspirational principles that articulate generic characteristics of the best kind of experiences intended for participants.

Expectations need to be set according to the resource level and expertise. A check list approach to quality should therefore be avoided.

Third: meaningful dialogue between parties in participatory arts projects (ie commissioners - funders - artists) is vital for establishing understanding and mutually recognising different expectations and responsibilities

Seidel et al's crucial observations on the interconnectedness of all stakeholders illuminate just how important communication is between partners in a participatory arts project. This is reinforced by findings from research by ArtWorks and IRISS showing the kind of weaknesses that can occur in the relationships between commissioning organisations and artists (Sellers 2014, Pattoni 2013, Pheby 2012, Kay 2012 etc).

The consistent message seems to be that the commissioning and delivery of participatory arts would benefit from a more robust partnership approach between stakeholders. When we realise that quality arises from a process starting from first principles, designing according to those principles and ending with reflection on the principles - then it is clear that stakeholder engagement needs to occur during all stages. 
There is a need for commissioners and employers (and where appropriate, funders) to help foster quality work by:

- Ensuring that basic pre-conditions are in place to enable the best quality work and outcomes;

- Evaluating realistically and according to pre-established aspirations for the work;

- Engaging in planning and design processes so as to input specialist knowledge about participant requirements.

It is clear from ArtWorks research that there is a great deal of impressive participatory arts work in the UK being delivered by artists and arts organisations and their partners. What has emerged from the most recent consultations is that the best working relationships go beyond a functional arrangement to develop trust, respect and creative space (Sheen 2014 cited by Sellers 2014:13). According to reporting by Sellers, both artists and employers/project managers testify that supportive and trusting relationships are vital to successful projects with quality outcomes.

In order to create optimum partnership conditions, employers - and particularly those outwith the arts sector - require support in understanding the value of participatory arts and the skills of the artists (Sellers 2014: 13 citing dha, 2014: 33). This is borne out by recent Arts Council England guidance which highlights different aims and objectives among partners. Its recommendations include:

- Discussing agendas openly

- Being willing to compromise

- Being specific about achievable aims (Sellers 2014: 16 citing Woolf/ACE 2014)

\section{TO CONCLUDE}

The research profiled in this paper demonstrates that:

1. Stakeholders have important influence on the outcomes for participants.

2. Artists can only control some elements of the quality of the experience

3. Varying expectations of the work need to be acknowledged and planned for

4. A holistic approach quality is required to enable the quality planning, design, resourcing and support required ultimately for delivering this work.

It is time to view participatory arts in a broader, more holistic context and recognise them as a phenomenon, perhaps akin to cultivating crops in a field. The quality of crops depends on the quality of the seeds, the soil, the fertiliser, as well as the skill of the agriculturist (not to mention favourable weather). There are lots of factors in play to produce the highest quality yield; if certain of these are not in place then regardless of the agriculturist's skill and effort, the optimum crop quality or yield cannot be achieved. 
Drawing together evidence from key studies profiled in this paper, it is increasingly clear that elements of a constructive quality system need to include:

- Shared stakeholder responsibility for quality

- Stakeholder engagement in stages of development process and evaluation

- Alignment between stakeholders on what constitutes quality, what quality experiences look like and how best to create these experiences in a specific setting

- Recognised conditions that are in place while the work is developed and implemented

- Shared aims, aspirations for the work between parties

- Realistic expectations for what the work can achieve, with different expectations between stakeholder groups communicated and understood

- A recognition of quality as a cycle of Continuous Quality Improvement enabling good practice to get better

These are all expressed and developed further as key learning points and recommendations in the Creative Scotland report Developing a Foundation for Quality Guidance for Arts Organisations and Artists in Scotland Working in Participatory Settings (Blanche 2014, Chapter 8).

The diagram below attempts to make a visual representation of an integrated system for quality, embodying all of these dynamics. It depicts a quality system in which key stakeholder-decision makers are, together, central to the achievement of quality; sharing an upward responsibility for setting and then meeting the aspirational goals of the work, and a simultaneous downward responsibility for ensuring the likely preconditions for quality are in place.

Figure 5: Measures needed to foster quality participatory arts work 
TO CONTINUALLY RAISE THE BAR FOR QUALITY, TOGETHER WE ASK:

WHAT KEY

OUTCOMES DID WE ACHIEVE?

HOW WELL DID WE MEET STAKEHOLDER NEEDS?

WHAT COULD WE DO

\section{SHARED ASPIRATIONS}

All parties agree and "buy into" the guiding aspirations and objectives for the work. Indicators are identified for what quality will look like. This means that stakeholders have a role in the early conception and planning phases of the work.

BETTER NEXT TIME?

DECISIONMAKERS SHARE RESPONSIBILTY FOR OUTCOMES, REFLECTION AND IMPROVEMENT

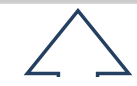

Upward focus on shared principles

upward focus on shared principles

\section{PARTNERS, EMPLOYERS} i.e. Those Just Outside the Room
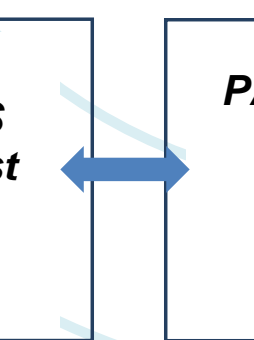

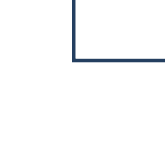

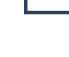

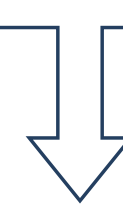

Downward responsibility for conditions

ARTISTS
ARIPANTS,

i.e. Those in the Room

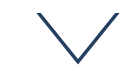

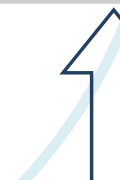

4

UNDERS, ORGANISATIONS

i.e. Those

Furthest from the Room

\section{RECOGNISE AND BUILD IN CONDITIONS FOR QUALITY}

i.e.

Resources

Time for planning, building relationships and implementing

project

Design around participants' needs and support

Realistic aims

Realistic expectations

Understanding of artist and partner roles

Buy-in and Trust by all parties

Democratic decision-making (artist-partner-participant)

Opportunities to reflect, adapt, evaluate 
A final question must be: what is the role for the participant as a stakeholder in participatory arts? There has been little presented here on the extent to which the participant can be expected to, or desired to, feed into the quality process, beyond making sure that their needs are communicated and recognised. Is there a role for the participant as an active partner through the entire process, in the sense of Seidel et al's theory? Further research is needed on how best to capture participant needs and engage them or - at least - encapsulate their perspective in the design and planning of work that is aimed at specific outcomes and principles.

The insights gained through the ArtWorks initiative and studies like the indepth analysis commissioned by Creative Scotland open up the possibilities for a dimensional shift in the way that participatory arts are perceived and funded. These are exciting times: Creative Scotland, having brought itself up to the minute understanding of quality as it relates to the participatory arts, and through its development of a new quality framework, occupies a natural position to lead the way towards a new, informed approach to quality in the participatory arts and an understanding on how best to foster it in partnership with other influential stakeholders.

\section{REFERENCES}

American Society for Quality (2014) The Global Voice of Quality, ASQ [webpage], accessed at: http://asq.org/learn-about-quality/basic-concepts.html

Bamford, A. (2010) Quality Assurance for the Creativity Portal. Scotland, UK: The Scottish Arts Council.

Blanche, R (2014) Developing a Foundation for Quality Guidance for arts organisations and artists in Scotland working in participatory settings: A report commissioned by Creative Scotland, September 2014, Edinburgh: Creative Scotland

Chartered Quality Institute (2013a) Introduction to Quality, [webpage] accessed at: http://www.thecqi.org/KnowledgeHub/Resources/Factsheets/Introduction-to-quality/ [accessed 11/11/2013]

Chartered Quality Institute (2013b) Quality for Continual Improvement, [webpage] accessed at: http://www.thecqi.org/KnowledgeHub/Resources/Factsheets/Continual-improvement/ [accessed 11/11/2013]

Consilium (2012) Skillset Research and Gap Analysis for Artists Working in Participatory Settings: Phase 2 Final Report, prepared by Consilium Research \& Consultancy, October 2012. Edinburgh: Creative Scotland

Dean, F (2012) Research report: Learning from Artworks Scotland Peer to Peer networks, prepared by Dr Fiona Dean, Freelance researcher, ArtWorks Scotland, October 2012. Edinburgh: Creative Scotland 
Dean, F (2013) ArtWorks Scotland Research Summary Quality Perspectives, Artists and Partners: Research Background and Key observations, Edinburgh: Creative Scotland

dha (2014b) ArtWorks Evaluation - Survey of Artists, dha

Downie, H (2011) Non-Formal Education in Scottish Traditional Music: Assessment of educational needs in organisations offering Scottish music tuition and future strategies for development, Commissioned by the Traditional Music Forum, produced by Heather Downie January 2011

HMIE (2006) How Good is our Community Learning and Development? Self Evaluation for Quality Improvement, HMIE 2006, Livingston: HMIE

Kay, S (2012) Artworks: Learning from the Research (Working Paper 1) Paul Hamlyn Foundation, Artworks, December 2012

Leighton-Kelly, S. (2012) Connecting Conversations 2011-12 Research Evaluation Report, ArtWorks London

Lord, P; Sharp, C; Lee, B; Cooper, L; Grayson, H (2012) Raising the Standard of Work by, With and For Children and Young People: Research and Consultation to Understand the Principles of Quality. Report for Arts Council England, National Foundation for Educational Research \& Shared Intelligence. Slough: NFER

Lowe, T. (2011). Audit of practice: Arts in participatory settings. Helix Arts on behalf of Artworks Northeast England: ArtWorks North East

Marino, L, ed. (2007) Basic principles and concepts for achieving quality, December 2007, TECHNICAL NOTE CMU/SEI-2007-TN-002, Software Engineering Institute

Matarasso, F (2013) Creative Progression: Reflections on quality in participatory arts, UNESCO Observatory Multi-Disciplinary Journal in the Arts, Vol 3, 3, 1-15

Pattoni, L (2013) The Arts in Scottish Social Services: Final Draft Report, December 2013, Institute for Research and Innovation in Social Services (IRISS)

Pheby, A. (2012) Focus Groups: Summary of findings, ArtWorks North East

Renshaw, Peter (2010). Engaged passions: searches for quality in community contexts. Delft: Eburon

Renshaw, P (2013) Being in Tune: A Provocation Paper. Seeking ways of addressing isolation and dislocation through engaging in the arts, September 2013, Guildhall School of Music and Drama/Barbican Centre 
Salamon, E (2013c) Artworks: Understanding Participants' Views (Working Paper 6), September 2013, London: Paul Hamlyn Foundation

Schwarz, M (2014) Artworks: Quality, Because We All Want to Do Better (Working Paper 8), January 2014, London: Paul Hamlyn Foundation

Seidel, S., Tishman, S., Winner, E., Hetland, L. and Palmer, P. (2010). The Qualities of Quality: Understanding Excellence in Arts Education.

Massachusetts: Harvard Graduate School of Education.

Sellers, E (2014) ArtWorks: Understanding the demand: building effective relationships between employers and artists (Working Paper 9), October 2014

Sheen, S. (2014) Addressing the Dynamic. The case study report, Trinity Laban Conservatoire of Music and Dance

Taylor, B (2013) Artworks: Artist Consultations (Working Paper 4), September 2013

White, M. (2010) Developing guidelines for good practice in participatory artsin-health-care contexts, Journal of Applied Arts and Health, Vol. 1 No. 2, 139155

Woolf, F. (2004) Partnerships for learning A guide to evaluating arts education projects, Arts Council England 